Document downloaded from:

http://hdl.handle.net/10251/105410

This paper must be cited as:

Doménech Carbó, A.; Capelo, S.; Piquero-Cilla, J.; Domenech Carbo, MT.; Barrio, J.; Fuentes, A.; Al Sekhaneh, W. (2016). Dating archaeological copper using electrochemical impedance spectroscopy. Comparison with voltammetry of microparticles dating. Materials and Corrosion. 67(2):120-129. doi:10.1002/maco.201408048

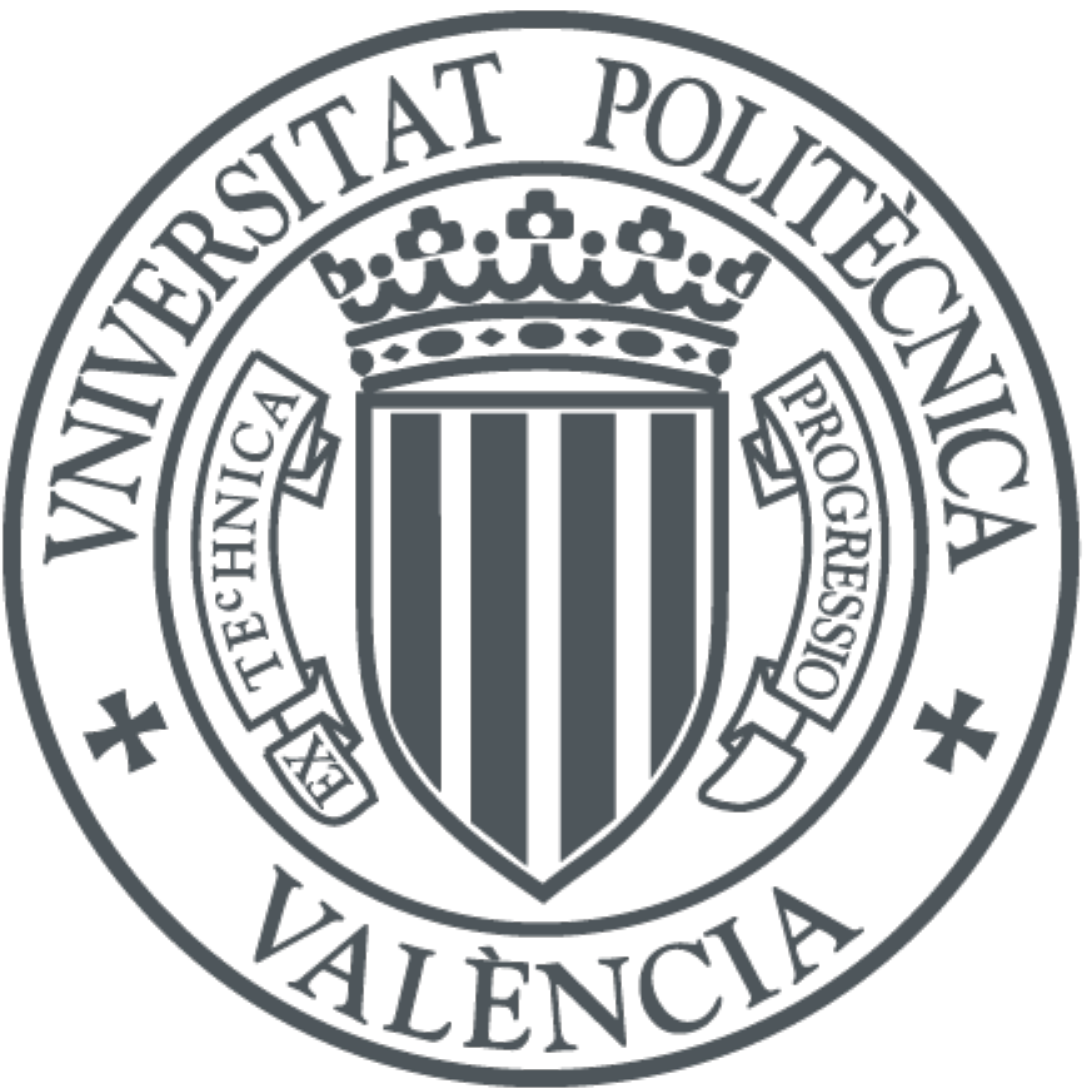

The final publication is available at

http://doi.org/10.1002/maco.201408048

Copyright John Wiley \& Sons

Additional Information 


\title{
Dating archaeological copper using electrochemical impedance spectroscopy. Comparison with voltammetry of microparticles dating
}

\author{
Antonio Doménech-Carbó*a, Sofia Capelo ${ }^{\mathrm{b}}$, Joan Piquero ${ }^{\mathrm{a}}$, María Teresa Doménech- \\ Carbóc $^{\mathrm{c}}$, Joaquín Barrio ${ }^{\mathrm{d}}$, Ángel Fuentes ${ }^{\mathrm{d}}$, Wassef Al Sekhaneh ${ }^{\mathrm{e}}$
}

${ }^{a}$ Departament de Química Analítica. Universitat de València. Dr. Moliner, 50, 46100 Burjassot (València) Spain.

b Centro de Ciências Moleculares e Materiais (CCMM), Faculdade de Ciências da Universidade de Lisboa, Campo Grande, C8, 1749-016 Lisboa, Portugal \& Departamento de Paisagem, Ambiente e Ordenamento, Escola de Ciências e Tecnología, Universidade de Évora, Rua Romão Ramalho 59, 7000-671 Évora Portugal

${ }^{c}$ Institut de Restauració del Patrimoni, Universitat Politècnica de València, Camí de Vera 14, 46022, València, Spain.

d Departmento de Prehistoria y Arqueología, Universidad Autónoma de Madrid, Madrid, Spain.

${ }^{\mathrm{e}}$ Faculty of Anthropology and Archaeology, Yarmouk University Irbid-Jordan.

\begin{abstract}
A methodology for dating copper/bronze archaeological objects aged under atmospheric environments using electrochemical impedance spectroscopy (EIS) is described. The method is based on the measurement of resistance associated to the growth of corrosion layers in EIS recorded upon immersion of the pieces in mineral water and applying a bias potential for the reduction of dissolved oxygen. Theoretical expressions for the time variation of such resistance following a potential rate law are presented. Equivalent expressions are derived and applied for estimating the variation of the tenorite/cuprite ratio from their specific voltammetric signals using voltammetry of microparticles data. Calibration curves were constructed from a set of well-documented coins.
\end{abstract}

Keywords: Archaeological copper; Electrochemical Impedance Spectroscopy; Voltammetry of microparticles; Dating; Conservation-restoration. 


\section{Introduction}

Absolute dating of archaeological objects and works of art is of obvious significance in the fields of archeometry and conservation/restoration of cultural heritage. Although this analytical target can be achieved for several materials using methods based on radioactive series and luminescence techniques [1-3], dating of metals can only be performed using the ${ }^{14} \mathrm{C}$ radiocarbon method when the metal sample is accompanied by traces of organic matter. The above methods can be complemented with those based on the analysis of the extent of ageing processes, pioneered by the Friedman and Smith's obsidian method for dating ceramics [4]. The same orientation was recently applied by Reich et al. [5] for dating archaeological lead using measurements of the Meissner effect.

Electrochemical dating was pioneered by Scholz, Brainina, Zakharchuk et al. [6] who proposed an electrochemical method for dating ceramic materials based on the voltammetry of microparticles (VMP), methodology. This is a solid-sate electrochemical technique developed by Scholz et al. which provides information on the mineralogical and chemical composition of sparingly soluble solids [7-9] whose high sensitivity prompted its extensive use for archaeometric analysis [10].

In previous reports, we have described the possibility of using the capabilities of VMP for dating archaeological lead [11] and copper/bronze artifacts [12]. In both cases, specific voltammetric signatures of corrosion products forming the primary and secondary patinas were determined, the ratio between the secondary and primary components growing according to potential laws, in agreement with studies on long-term corrosion of metals [13-15]. Combination of VMP with electrochemical impedance spectroscopy, a technique used for monitoring corrosion in archaeological metals [16-19], was previously discussed to date archaeological lead [20]. These methods involve a series of simplifying assumptions, in particular that the ageing occurred under 'smooth', uniform conditions of corrosion. Irregularities in the corrosion conditions and formation of different corrosion products, however, can alter significantly the ageing pattern thus resulting in the nonapplicability of proposed dating methods. This is particularly relevant in the case of copper and bronze objects, for which the proposed methodology is based on the determination of the tenorite/cuprite ratio [12]. In this case, the frequent appearance of localized or even 
extensive corrosion yielding malachite, atacamite, brochantite, etc. can result in distorted dating [12]. The purpose of the current report is to describe a methodology for correcting such effects using EIS based on the measurement of resistance associated to the corrosion layers progressively growing with time under assumed uniform corrosion conditions. In order to apply for dating archaeological objects, EIS were recorded upon immersion of the pieces in mineral water, a procedure recommended ensuring their morphological, structural and chemical integrity [21] and applying a bias potential for the reduction of dissolved oxygen.

The current formulation is based on studies on the electrochemical response of archaeological copper and bronze [22-25] and long-term metal corrosion [26-31]. Here, the modeling of corrosion processes was formulated in terms of the kinetics of the metal/primary patina and primary patina/secondary patina interfaces [32] so that theoretical expressions for the time variation of EIS and VMP parameters were derived.

EIS analysis can be viewed in the context of modeling of the corrosion of metals. In particular, the High Field Model (HFM) [24] and the Point Defect Model (PDM) [3336], which provides a good account of the growth of the passive films on metal surfaces predicting the evolution of the corrosion process as a function of time, as recently reviewed [37]. A calibration curve was constructed from a set of coins from a private collection. Calibration curves from EIS and VMP data were compared and applied to date a fragment from a bronze sculpture providing from the Roman site of Valeria (Spain, $1^{\text {st }}$ century AC) and a series of copper vessels, dated ca. 1260 (Mamluk period) from Jordan.

\section{Experimental}

\section{Electrochemical instrumentation and procedures}

Voltammetry of microparticles experiments were performed at sample-modified paraffinimpregnated graphite electrodes using commercial graphite bars (Staedtler Mars 200 HB, $2.0 \mathrm{~mm}$ diameter) immersed into $0.25 \mathrm{M} \mathrm{HAc/NaAc}$ aqueous solution at $\mathrm{pH} 4.75$, previously degasified by bubbling Ar. EIS experiments were performed in $0.10 \mathrm{M} \mathrm{NaClO}_{4}$ and mineral water from Bejís (Comunitat Valenciana, Spain) using a modified cell, adapted for partial immersion of metallic objects, already described [38]. All 
electrochemical measurements were carried out using a CH I660 potentiostat. A standard three-electrode arrangement was used with a platinum auxiliary electrode and a $\mathrm{Ag} / \mathrm{AgCl}$ $(3 \mathrm{M} \mathrm{NaCl})$ reference electrode. For VMP measurements, few nanograms of sample were abrasively transferred to the surface of the graphite bar using the 'one-touch' sampling procedure already described [39-41].

EIS measurements were performed, using the aforementioned instrument, in the 0.01 to $100000 \mathrm{~Hz}$ frequency range with amplitude of $10 \mathrm{mV}$ at different potentials between +1.00 and $-1.00 \mathrm{~V}$ upon partial immersion of the archaeological piece into the electrolyte. For this purpose, the coins used for calibration purposes were suspended from an insulating tong and immersed to a certain depth and served as a working electrode upon connection to a conventional crocodile clamp. For each piece, experiments were performed for three different immersion depths and varying the position of the clamp but maintaining an immersed area of ca. $1 \mathrm{~cm}^{2}$. Three repeated experiments were performed for each one of these (depth plus clamp position) configurations. Prior to each EIS experiment, an equilibration time of 15 min was taken. Air-saturated mineral water from Bejís (Valencian Community, Spain) was used (Composition: dry residual $159 \mathrm{mg} / \mathrm{L}, \mathrm{HCO}_{3}{ }^{-}: 163 \mathrm{mg} / \mathrm{L}$, $\mathrm{SO}_{4}{ }^{2-}: 16 \mathrm{mg} / \mathrm{L}, \mathrm{Cl}^{-}: \mathrm{mg} / \mathrm{L}, \mathrm{SiO}_{2}: 4.3 \mathrm{mg} / \mathrm{L}, \mathrm{Ca}^{2+}: 47 \mathrm{mg} / \mathrm{L}, \mathrm{Mg}^{2+}: 6.2 \mathrm{mg} / \mathrm{L}, \mathrm{Na}^{+}: 2.8$ $\mathrm{mg} / \mathrm{L}$.

\section{Samples}

A series of coins from the Antonio Doménech-Francés private collection were used. The coins, all of low numismatic value, accomplished several basic conditions: i) uniform aspect with no features of strong localized corrosion; ii) existence of no previous cleaning/stabilization treatments. The basic data for the studied coins are listed in Table 1. Two archaeological samples, consisting of a fragment of a bronze sculpture from the site of Valeria ( $1^{\text {st }}$ century AC, Spain) and powdered corrosion products extracted in Jordan from bronze vessels of the Mamluk period (see Figure 1) were also used. In both cases, only VMP measurements were performed. Control experiments were performed in 5 eurocent coins distinguishing between 'fresh' (retaining the metallic luster) and 'aged' (with opaque surface). 


\section{Theoretical model}

\section{Kinetic equations}

It will be assumed that, under 'ordinary' atmospheric corrosion conditions, copper and bronze samples form a primary patina of cuprite $\left(\mathrm{Cu}_{2} \mathrm{O}\right)$ which subsequently grows being partially oxidized to tenorite $(\mathrm{CuO})$ forming a secondary patina, as schematically depicted in Figure 2. The $\mathrm{Cu}_{2} \mathrm{O}$ to $\mathrm{CuO}$ oxidation is a thermodynamically spontaneous process favored by the prolonged contact of the artifacts with a $\mathrm{CO}_{2}$-rich atmosphere as well as with calcareous materials [42-44]. The proposed kinetic model is based on the assumptions [32]: i) there are simultaneous/consecutive interfacial reactions occurring at the metal/primary patina (M/PP) and primary patina/secondary patina (PP/SP) boundaries; ii) kinetic potential laws apply for such reactions. This second hypothesis is supported by abundant literature on long-term corrosion of metals [35-41]. Introducing the mole amount of primary corrosion product by surface unit, $y$, the rate equation for the patination process at the base metal/primary patina interface can be expressed as:

$$
\left(\frac{\mathrm{d} y}{\mathrm{~d} t}\right)_{\mathrm{BM} / \mathrm{SP}}=K_{1} y^{-\alpha}
$$

We will be also assumed that the secondary tenorite patina is formed at the expense of the primary cuprite layer when the primary patina is thick enough so that the formation of tenorite (at an amount of $z$ mole per surface unit) occurs independently from the kinetics of processes occurring at the metal/primary patina interface. As far as the overall reaction is $2 \mathrm{Cu}_{2} \mathrm{O}+\mathrm{O}_{2} \rightarrow 4 \mathrm{CuO}$, one can write the rate equations [12]:

$$
-\left(\frac{\mathrm{d} y}{\mathrm{~d} t}\right)_{\mathrm{PP} / \mathrm{SP}}=K_{2} y^{-\beta} ;\left(\frac{\mathrm{d} z}{\mathrm{~d} t}\right)_{\mathrm{PP} / \mathrm{SP}}=2 K_{2} z^{-\beta}
$$

Integration of the second equation between $z=0$ and $y$ and $t=0$ and $t$ leads to:

$$
z=\left[(1+\beta) 2 K_{2} t\right]^{\frac{1}{1+\beta}}
$$

Assuming that the process of formation of secondary patina starts when an amount $y_{0}$ of primary patina is formed, the net amount of cuprite at a time $t$ will be:

$$
y=\left[(1+\alpha) K_{1} t\right]^{\frac{1}{1+\alpha}}+y_{\mathrm{o}}{ }^{1+\beta}-\left[(1+\beta) K_{2} t\right]^{\frac{1}{1+\beta}}
$$




\section{Kinetic analysis of VMP data}

As already described, the voltammetric response of samples from the corrosion layers in contact with aqueous acetate buffer consists of cathodic peaks at -0.10 (I) and ca. $-0.45 \mathrm{~V}$ vs. $\mathrm{Ag} / \mathrm{AgCl}$ (II) $[12,32]$, as shown in Figure 3 for an archaeological sample. The first signal corresponds to the reduction of cuprite, malachite, atacamite, etc. while the second can be attributed to the reduction of tenorite. Accordingly, the above equations can be correlated with voltammetric data assuming that the peak current (or the peak area) of the processes I and II is proportional to the respective amount of secondary and primary patina by unit of surface area, one can write:

$$
\begin{gathered}
i_{\mathrm{p}}(\mathrm{I})=g G_{\mathrm{I}}\left[(1+\alpha) K_{1} t\right]^{\frac{1}{1+\alpha}}+y_{\mathrm{o}}{ }^{1+\beta}-\left[(1+\beta) K_{2} t\right]^{\frac{1}{1+\beta}} \\
i_{p}(I I)=g G_{I I}\left[(1+\beta) 2 K_{2} t\right]^{\frac{1}{1+\beta}}
\end{gathered}
$$

In these equations, $G_{\mathrm{I}}, G_{\mathrm{II}}$ represent 'electrochemical' constants depending on the electrochemical process and the conditions (electrolyte, square wave frequency, etc.) in which the corresponding signal is recorded and $g$ denotes the amount of sample attached to the electrode. Accordingly, the $i_{\mathrm{p}}(\mathrm{II}) / i_{\mathrm{p}}(\mathrm{I})$ ratio would be:

$$
\frac{i_{p}(I I)}{i_{p}(I)}=\frac{G_{I I}}{G_{I}}\left[\frac{\left[(1+\beta) 2 K_{2} t\right]^{\frac{1}{1+\beta}}}{y_{o}^{1+\beta}+\left[(1+\alpha) K_{1} t\right]^{\frac{1}{1+\alpha}}-\left[(1+\beta) K_{2} t\right]^{\frac{1}{1+\beta}}}\right]
$$

Assuming $\alpha \approx \beta \approx \delta$, one can use the approximate expression:

$$
\frac{i_{p}(I I)}{i_{p}(I)} \approx \frac{G_{I I}}{G_{I}}\left[\frac{\left[(1+\beta) 2 K_{2} t\right]^{\frac{1}{1+\beta}}}{y_{o}^{1+\delta}+\left[(1+\delta)\left(K_{1}-K_{2}\right) t\right]^{\frac{1}{1+\delta}}}\right]
$$

As far as both the $i_{\mathrm{p}}(\mathrm{I})$ and $i_{\mathrm{p}}(\mathrm{II})$ currents were measured from the base line of the peak I, as previously described, a constant correction factor, $G$, has to be added. Then, the final calibration equation was: 


$$
\frac{i_{p}(I I)}{i_{p}(I)} \approx G+\frac{G_{I I}}{G_{I}}\left[\frac{\left[(1+\beta) 2 K_{2} t\right]^{\frac{1}{1+\beta}}}{y_{o}^{1+\delta}+\left[(1+\delta)\left(K_{1}-K_{2}\right) t\right]^{\frac{1}{1+\delta}}}\right]
$$

A more realistic description would include the formation of other secondary corrosion products such as atacamite, malachite, etc. which are formed in the secondary patina competing with the formation of tenorite. One can assume that a rate law of the type:

$$
\left(\frac{\mathrm{d} w}{\mathrm{~d} t}\right)_{\mathrm{PP} / \mathrm{SP}}=K_{3} w^{-\gamma}
$$

also applies. Assuming that this secondary product provides a reduction signal essentially indistinguishable from that of cuprite, as occurring for azurite, malachite, brochantite and the minerals of the atacamite group $[45,46]$, that the reactions of formation of tenorite and that product occurs in separate regions of the patina (in agreement with the observation of separate corroded regions in coins, etc.), and that all the exponents of the individual potential rate laws are similar, the $i_{\mathrm{p}}(\mathrm{II}) / i_{\mathrm{p}}(\mathrm{I})$ ratio $(=I)$ should be:

$$
\frac{i_{p}(I I)}{i_{p}(I)} \approx G+\frac{G_{I I}\left[(1+\beta) K_{2} t\right]^{\frac{1}{1+\beta}}+G_{I}\left[(1+\gamma) K_{3} t\right]^{\frac{1}{1+\gamma}}}{G_{I}\left[y_{o}^{1+\delta}+(1+\delta)\left(K_{1}-K_{2}-K_{3}\right) t\right]^{\frac{1}{1+\delta}}}
$$

\section{Kinetic analysis of EIS data}

For reasons of repeatability, EIS data were taken at potentials where the reduction of the corrosion patinas could occur to some extent (vide infra). Such data can be interpreted using an equivalent circuit in which the coin behaves as a cathode connected to the external anode completing the electrochemical cell, thus differing from those usually used, operating at the OCP, where both anodic and cathodic processes were accounted $[18,19]$. Then, the metal forming the coin will be assumed to be entirely covered by a passive layer of cuprite and a secondary patina constituted by other products.

Attempts to fit experimental data to models typically used for modeling corroded metal surfaces [47-50] were unsuccessful. Accordingly, 
Attempts to fit experimental data to models typically used for modeling corroded metal surfaces [47-50] were unsuccessful so that models used to describe layered mixtures of metal oxides created by anodic growth on metal surfaces [51-53] and other layered systems such as dye-sensitivized solar cells [54] and polyaniline films [55], were tested.

The resulting equivalent circuit, schematized in Figure 4, includes a solution resistance $\left(R_{\mathrm{s}}\right)$, a charge transfer resistance at the metal/primary corrosion patina interface $\left(R_{\mathrm{mp}}\right)$ connected in parallel to a double layer capacitive element $\left(Q_{\mathrm{dl}}\right)$ and in series to an impedance composed by a parallel association of a constant phase element $\left(Q_{\mathrm{ps}}\right)$, a resistance $\left(R_{\mathrm{ps}}\right)$, both describing the effect of the secondary corrosion layer/electrolyte interface, and a series combination of a solution/secondary patina resistance $\left(R_{\mathrm{ss}}\right)$ and a Warburg element. This last would be representative of the resistance and charge diffusion through the secondary patina, assumed to have some porosity. The above main sub-circuit was accompanied by a parallel combination of a resistance $\mathrm{R}_{1}$ and a constant phase element $\mathrm{Q}_{1}$, representative of the clamp-coin connection, as used for modeling the electrolyte influence in dye-sensitivized solar cells [54]. Constant phase elements were used in place of capacitors in order to account for non-ideal capacitive behavior of the interfacial charge transfer mechanism associated with the nonuniform distribution of current which arises as a result of surface roughness, impurities, dislocations or grain boundaries [47-50].

Using this model, satisfactorily fitted to experimental data (vide infra), one can expect that the resistance associated to the primary plus secondary patina, $R_{\mathrm{ps}}$, increased upon increasing the total thickness of the corrosion layers. Adapting the model from Lee and Pyun [56], previously described for highly corroded iron [38], the resistance by unit of surface area of primary and secondary patinas, $R_{\mathrm{p}}(\mathrm{t}), R_{\mathrm{s}}(\mathrm{t})$, could be expressed by means of single expressions in terms of the thickness of such layers at time $t$, respectively, $\delta_{\mathrm{p}}(t), \delta_{\mathrm{s}}(t)$, and the conductivities of the materials forming the patinas, $\sigma_{\mathrm{p}}, \sigma_{\mathrm{s}}$. In the case of moderate copper/bronze corrosion, one can assume that a nonporous primary patina forms a continuous cover on the base metal so that:

$$
R_{\mathrm{p}}(t)=\delta_{p}(t) / \sigma_{\mathrm{p}}
$$

The secondary patina, however, can have some porosity. To account the possible permeation of the secondary corrosion layer by the electrolyte, the porosity, defined as 
the volume fraction occupied by the corrosion products [49,50], of the different layers was introduced. Accordingly, the contribution to the resistance of the electrolyte filling the pores is expressed in terms of the electrolyte conductivity $\sigma_{\mathrm{el}}$. Finally, the degree of coverage of the primary patina by the secondary one is represented by means of the fraction of covered surface area, $\theta_{\mathrm{s}}$. As a result, the resistance by surface area unit of the secondary patina would be:

$$
R_{s}(t)=\frac{\delta_{\mathrm{s}}(t)}{\vartheta_{s}(t)}\left\{\frac{\chi_{s}(t)}{\sigma_{s}}+\frac{\left[1-\chi_{s}(t)\right]}{\sigma_{e l}}\right\}
$$

In the case of moderate copper/bronze corrosion, one can simplify the above expression upon assuming that the porosity of the corrosion layers is low $\left(\chi_{\mathrm{s}} \approx \chi_{\mathrm{p}} \approx 1\right)$ and that the coverage of the primary patina by the secondary patina is complete $\left(\theta_{\mathrm{s}} \approx 1\right)$. Combining the above equations with the kinetic equations (3) and (4), and introducing the densities of the primary and secondary patinas, $\rho_{\mathrm{p}}, \rho_{\mathrm{s}}$, one obtains:

$$
R_{\mathrm{p}}(t)+R_{s}(t)=\frac{y_{o}^{1+\beta}}{\rho_{p} \sigma_{p}}+\frac{\left[(1+\beta) K_{1} t\right]^{\frac{1}{1+\beta}}}{\rho_{s} \sigma_{s}}+\frac{\left[(1+\alpha) K_{1} t\right]^{\frac{1}{1+\alpha}}-\left[(1+\beta) K_{2} t\right]^{\frac{1}{1+\beta}}}{\rho_{p} \sigma_{p}}
$$

When $\alpha \approx \beta \approx \gamma$, one can take as a reasonable approximation:

$$
R_{\mathrm{p}}(t)+R_{s}(t)=\frac{y_{o}^{1+\beta}}{\rho_{p} \sigma_{p}}+[(1+\gamma) t]^{\frac{1}{1+\gamma}}\left[K_{1}^{\frac{1}{1+\gamma}}\left(\frac{1}{\rho_{s} \sigma_{s}}+\frac{1}{\rho_{p} \sigma_{p}}\right)-\frac{K_{2}^{\frac{1}{1+\gamma}}}{\rho_{p} \sigma_{p}}\right]
$$

Equation (15) defines a single potential rate law. It should be emphasized, however, that apart from the aforementioned simplifying assumptions, it is presumed that the primary and secondary corrosion layers remain homogeneous during the entire corrosion process; i.e., that their densities and conductivities are time-independent.

\section{Errors}

Using the usual theory for error propagation, and assuming fixed values of the exponents in the kinetic equations, we can consider that the relative uncertainty in the time measurement, $\Delta t / t$, will be function of the uncertainty in the peak current ratio and the time. Introducing $I=i_{\mathrm{p}}(\mathrm{II}) / i_{\mathrm{p}}(\mathrm{I})$ and taking: 


$$
I=\frac{i_{p}(I I)}{i_{p}(I)}=\left[\frac{A t^{a}}{B+t^{b}}\right]
$$

we can obtain:

$$
\frac{\Delta t}{t}=\left(\frac{\Delta I}{I}\right)\left[\frac{B+t^{b}}{a B+(a-b) t^{b}}\right]
$$

where $\Delta I / I$, represents the relative uncertainty of the peak current ratio which in turn could be considered as time-dependent. Under the VMP experimental conditions, one can assume that the uncertainty in the individual measurements of $i_{\mathrm{p}}(\mathrm{I})$ and $i_{\mathrm{p}}(\mathrm{II})$ is the same $\left(\Delta i_{\mathrm{p}}\right)$ so that:

$$
\left(\frac{\Delta I}{I}\right)=\Delta i_{\mathrm{p}}\left(\frac{1}{i_{p}(I)}+\frac{1}{i_{p}(I I)}\right)
$$

Assuming that the sum of the above peak currents is the same in all experiments (a reasonable assumption for VMP experiments performed via 'one-touch' sampling), one can obtain:

$$
\left(\frac{\Delta I}{I}\right)=\left(\frac{\Delta i_{p}}{i_{p}}\right) \frac{(1+I)^{2}}{I}
$$

As far as the relative uncertainty in peak current measurements, $\Delta i_{\mathrm{p}} / i_{\mathrm{p}}$, can be taken as constant, one can arrive to the following relationship:

$$
\frac{\Delta t}{t}=\left(\frac{\Delta i_{p}}{i_{p}}\right)\left[2+\frac{A t^{a}}{B+t^{b}}+\frac{B+t^{b}}{A t^{a}}\right]\left[\frac{B+t^{b}}{a B+(a-b) t^{b}}\right]
$$

Which express the theoretical time variation of the uncertainty in time estimations from VMP data. Figure 5a shows the theoretical variation of the 'intrinsic' contribution of the aging (from Eq. (17)), peak current ratio (from Eq. (19)) and the resulting uncertainty (Eq. (20)) assuming for $\Delta i_{\mathrm{p}} / i_{\mathrm{p}}$ a reasonable value of $2 \%$ using $A=2.3 ; B=1000$, and $a=$ $b=0.95$.

In the case of EIS experiments, we can rewrite eq. (15) as: 


$$
R(t)=C+D t^{\frac{1}{1+\gamma}}
$$

Taking the uncertainty in resistance measurements, $\Delta R / R$, as a constant, the relative uncertainty in time measurements at a given $\gamma$ value would be:

$$
\frac{\Delta t}{t}=(1+\gamma)\left(\frac{\Delta R}{R}\right)\left[\frac{C+D t^{\frac{1}{1+\gamma}}}{D t^{\frac{1+2 \gamma}{1+\gamma}}}\right]
$$

Here, the 'intrinsic' contribution of aging, given by the term in brackets in Eq. (22) decreases with time. Our experimental data (vide infra) using replicate EIS experiments revealed that the relative uncertainty of the resistance increased upon increasing time, as a result of the increase in the dispersion of the measurements. The time variation of such terms and the resulting $\Delta t / t$ are depicted in Fig. 5b taking $C=500, D=100, \gamma=0.07$.

It is pertinent to note that additional factors of error should be accounted. In particular, the uncertainty in the surface area immersed, possibly accompanied by microchanges in the position of the wet/dry line of the coin during EIS measurements, thus enhancing the uncertainty associated to resistance measurements using EIS data.

\section{Results and discussion}

\section{VMP experiments}

VMP experiments at paraffin-impregnated graphite electrodes modified with samples taken from the 'one-touch' technique reproduced the features previously described $[12,45,46]$. Figure 3 shows the SWV for samples from a copper vessel (Jordan, Mamluk period) in contact with aqueous acetate and phosphate buffers. In acetate buffer, cathodic peaks at ca. $-0.10 \mathrm{~V}$ vs. $\mathrm{Ag} / \mathrm{AgCl}$ (I) and $-0.45 \mathrm{~V}$ (II) appear. The first peak corresponds to the reduction of cuprite $\left(\mathrm{Cu}_{2} \mathrm{O}\right)$, the ubiquitous component of the primary copper patina [57,58], accompanied by copper hydroxicarbonates (azurite, malachite) and hydroxichlorides (the atacamite group of minerals), whereas the peak II corresponds to the reduction of tenorite $(\mathrm{CuO})$. In few cases, nantokite $(\mathrm{CuCl})$ appears as a corrosion product, 
characterized by a cathodic peak at ca. $-0.30 \mathrm{~V}$ (III) which becomes particularly well defined in phosphate buffer [59].

As previously described, the tenorite to cuprite ratio, estimated from the peak current ratio between the signals II and $\mathrm{I}, i_{\mathrm{p}}(\mathrm{II}) / i_{\mathrm{p}}(\mathrm{I})$, can be used to estimate the age of a copper object. Figure 6 shows the position of the archaeological samples in this study, a fragment of a bronze sculpture from the site of Valeria ( $1^{\text {st }}$ century AC, Spain) and corrosion products extracted from bronze vessel of the Mamluk period (see Figure 1), in the calibration curve constructed from already reported data [12]. The age of such objects determined from the calibration graph agrees well with that determined from the archaeological context.

\section{EIS experiments}

EIS experiments were performed in this study upon immersion of the coins in mineral water as described in the Experimental section. To ensure that the recorded data fulfill the constraints of the linear systems theory (LST), the Kramers-Kronig (K-K) transforms were applied [60,61], thus denoting that, under our experimental conditions, the LST constraints were satisfied.

EIS data were recorded for eurocent coins using different bias potentials and electrolyte media, including $0.10 \mathrm{M}$ aqueous phosphate buffer at $\mathrm{pH} 7.0$ and $0.10 \mathrm{M} \mathrm{NaClO}_{4}$. After equilibration for $15 \mathrm{~min}$, the EIS curves showed an excellent repeatability for replicate experiments performed for a fixed set of conditions. However, experiments varying the immersion level and the position of the connecting clamp, although maintaining the general profile of Nyquist and Bode plots, produced significant variations in the numerical values of the impedance parameters. These features can be seen in Figure 7, where the Nyquist and Bode plots of replicate experiments for a eurocent coin in two different immersion plus clamp configurations are shown. For reasons of repeatability and by the non-aggressive characteristic of the electrolyte, mineral water was selected and the wet area was fixed to $1 \mathrm{~cm}^{2}$. As previously noted, the uncertainty in the immersed area and microfluctuations in the wet/dry line would influence significantly the values of several EIS parameters. The potential of $-0.60 \mathrm{~V}$ was selected for such EIS experiments because at this potential there is opportunity for promoting the 
electrochemical reduction of dissolved oxygen [62,63], which could act as a redox probe, with minimal influence of the proton-assisted reduction of copper corrosion products. This was confirmed by voltammograms recorded for eurocent coins in mineral water.

As previously noted, experimental EIS data diverged from models typically used for modeling corroded metal surfaces [47-50]. This can be attributed, at least partially, to the influence of the clamp contact which is mainly responsible for the high-frequency loop in the Nyquist graphs and the increase of phase angle in the same region of the Bode plot (see Figs. 7 and 8).

Figure 8 compares the experimental Nyquist and Bode plots for coin ADF09 with theoretical ones from the model in Figure 4. The Nyquist representations consisted in two consecutive capacitive-depressed semicircle loops whereas the phase angle exhibits a maximum at low-intermediate frequencies (vide infra) subsequent to an initial maximum at high frequencies. As can be seen in Figure 8, the proposed equivalent circuit provides a satisfactory fit with experimental data for archaeological metal pieces after washing. Unfortunately, using the aforementioned modeling for replicate EIS experiments for a given coin produced significant variations in the values of the circuit elements from data fitting. Representative values from three replicate experiments were: $R_{\mathrm{S}}=50 \Omega \mathrm{cm}^{-2}, R_{1}=1900 \Omega \mathrm{cm}^{-2}, Q_{1}=4.2 \times 10^{-9} \mathrm{~F} \mathrm{~cm}^{-2}, n_{\text {corr }}=0.90, R_{\mathrm{mp}}=8400 \Omega$ $\mathrm{cm}^{-2}, R_{\mathrm{ps}}=25000 \Omega \mathrm{cm}^{-2}, R_{\mathrm{ss}}=6 \mathrm{k} \Omega \mathrm{cm}^{-2}, W=1.0 \times 10^{-12} \Omega \mathrm{cm}^{-2}, Q_{\mathrm{ps}}=2.5 \times 10^{-11} \mathrm{~F}$ $\mathrm{cm}^{-2}, n_{\text {pas }}=0.76, Q_{\mathrm{dl}}=2.9 \times 10^{-6} \mathrm{~F} \mathrm{~cm}^{-2}, n_{\text {corr }}=0.70$. The relatively low averaged value of the solution resistance could result from the 'clamp effect' associated to the coin contact. This effect is influential on the EIS response at high frequencies, just where the solution resistance is determinant of the total impedance, and probably produces an underestimate of the solution resistance.

As previously noted, EIS experiments were sensitive to changes in the immersion level and position of the clamp connection of the coins. This resulted, as described for highly corroded iron [28], in regular variations between different EIS parameters for each one of the coins. This can be seen in Figure 9, where the experimental values of the maximum phase angle, $\varphi_{\max }$, and the logarithm of the total impedance at $0.1 \mathrm{~Hz}\left(Z_{-1}\right.$ in the 
following) are depicted for replicate EIS experiments from 'fresh' and 'aged' eurocent coins and coin ADF06, dated in 1916. $Z_{-1}$ would be roughly representative of the limiting interfacial resistance at the very low frequency $\left(Z_{\text {real, } f \rightarrow 0}\right)$, resulting from the sum of the contributions of the ionic resistance of the electrolyte and the electronic resistance contribution from the electrode, as has been described for porous electrodes [64].

For dating purposes, the variation with the corrosion time of the EIS parameters was studied. Attempts to construct calibration plots resulted in graphs such as in Figure 10, where the variation of the maximum phase angle at intermediate frequencies with the age of several coins is depicted. Data for replicate EIS experiments resulted, as previously noted, in large dispersions so that, although data suggest a systematic variation of frequency-dependent impedance parameters with time, even fitting reasonable to potential laws (see continuous curve in Figure 10), the accuracy for dating purposes was in general low. Similar results were obtained using the module of the impedance at the low frequency limit, in this case suffering from relatively high data dispersion in the spectra (see Figs. 7 and 8). The proposed theoretical modeling, however, produced a reasonable agreement with experimental data using resistance parameters. This can be seen in Figure 11 where it is depicted the time variation of the mean value of the apparent charge transfer resistance, $R_{\mathrm{ct}}{ }^{\text {app }}$, from five replicate EIS experiments. This quantity, which would be equivalent to the sum of $R_{\mathrm{p}}(t)$ plus $R_{\mathrm{s}}(t)$ in Eqs. (14) and (15), can be derived from the fitting of experimental EIS data to the equivalent circuit in Fig. 4 or, approximately, from the diameter of the main loop in the Nyquist plots such as in Fig. 8a. The last criterion provided minor dispersion than the former and was used for calibration purposes. The corresponding calibration graph is shown in Fig. 11 where experimental $R_{\mathrm{ct}}{ }^{\text {app }}$ data for coins in this study is plotted as a function of the corrosion time. One can see in this figure that, with except of few coins showing large separations, the majority of the can be placed close to a potential calibration curve fitting to Eq. (21) inserting $C=500, D=100, \gamma=0.07$. Correlation with VMP experiments showed that coins abruptly separated from this tendency are those containing relatively high amounts of corrosion products other than cuprite and tenorite. 


\section{Conclusions}

A method for dating copper/bronze archaeological objects based on electrochemical impedance spectroscopy (EIS) measurements is described and tested for a series of coins of known age. EIS measurements for coins in contact with mineral water under the application of a bias potential able to promote the electrochemical reduction of dissolved oxygen provide spectra which can be modeled in terms of resistance and constant phase elements associated to the metal/primary corrosion patina interface and the secondary corrosion layer/electrolyte interface. The resistance of the primary and secondary patinas calculated from experimental EIS data for a series of coins since the $16^{\text {th }}$ century can be correlated with the age of the coin assuming uniform conditions of corrosion, thus providing resistance/time calibration curves usable for dating purposes.

Calibration curves from EIS data were satisfactorily compared with those obtained from the measurement of the variation of the tenorite/cuprite ratio using the specific voltammetric signals of such compounds by means of the voltammetry of microparticles (VMP) technique. Calibration graphs can be fitted in both cases to potential rate laws with a common exponent of 0.07 . The application of such techniques for dating archaeological copper/bronze artifacts is conditioned, however, by the uncertainty in the electrochemical measurements and the validity of the simplifying assumptions used to correlate electrochemical parameters with aging time. Corrosion under smooth, uniform atmospheric conditions is required for a judicious application of the described methodology in the archaeology domain.

Ackonwledgements: Financial support from the MEC Projects CTQ2011-28079-CO3-01 and 02 and CTQ2014-53736-C3-2-P which are supported with ERDF funds is gratefully acknowledged. 


\section{References}

[1] M.J. Aitken, Science-Based Dating in Archaeology. Longman, New York, chapter 8.

[2] M.A. Geyh, H. Schleicher, Physical and Chemical Dating Methods and Their Application. Springer, Berlin-Heidelberg, 1990.

[3] C. Renfrew, P. Bahn, Archaeology: Theory, Methods and Practice. Thames \& Hudson, London, 1991, chapter 4.

[4] I. Friedman, R.L. Smith, Amer. Antiq. 1960, 25, 476.

[5] S. Reich, G. Leitus, S. Shalev, New J. Phys. 2003, 5, 99.1.

[6] F. Scholz, U. Schröder, S. Meyer, Kh.Z. Brainina, N.F. Zakharchuk, N.V. Sobolev, O.A. Kozmenko, J. Electroanal. Chem. 1995, 385, 139.

[7] F. Scholz, B. Meyer, Voltammetry of solid microparticles immobilized on electrode surfaces in Electroanalytical Chemistry, A Series of Advances, Bard AJ, Rubinstein I, Eds, Marcel Dekker, New York, 1998, vol. 20, pp. 1-86

[8] F. Scholz, U. Schröder, R. Gulaboski, A. Doménech-Carbó, Electrochemistry of Immobilized Particles and Droplets, Springer, Berlin-Heidelberg, 2014.

[9] A. Doménech-Carbó, J. Labuda, F. Scholz, Pure Appl. Chem. 2013, 85, 609.

[10] A. Doménech-Carbó, M.T. Doménech-Carbó, V. Costa, Electrochemical methods applied to archaeometry, conservation and restoration, Monographs in Electrochemistry Series, F. Scholz, Edit, Springer, Berlin-Heidelberg, 2009.

[11] A. Doménech-Carbó, M.T. Doménech-Carbó, M.A. Peiró-Ronda, Anal. Chem. 2011, 83,5639 .

[12] A. Doménech-Carbó, M.T. Doménech-Carbó, S. Capelo, T. Pasíes, I. MartínezLázaro, Angew. Chem. Int. Ed., 2014, 53, 9262.

[13] M. Benarie, F.L. Lipfert, Atmos. Environ. 1986, 20, 1947.

[14]S. Feliu, M. Morcillo, Atmospheric corrosion testing in Spain, in W.H. Aylor, Ed. Atmospheric Corrosion, John Wiley and Sons, New York, 1982, pp. 913-921.[15] H. Strandberg, Atm. Envir. 1998, 32, 3521.

[16] E. Cano, D. Lafuente, D.M. Bastidas, J. Solid State Electrochem. 2010, 14, 381.

[17] M. Hernandez-Escampa, J. Gonzalez, J. Uruchurtu-Chavarin, J. Appl. Electrochem. 2010, 40, 345 .

[18] E. Angelini, S. Grassini, M. Parvis, F. Zucchi, Surf. Interf. Anal. 2012, 44, 942.

[19] S. Grassini, E. Angelini, M. Parvis, M. Bouchar, P. Dillmann, D. Neff, Appl. Phys. A 2013, 113, 971. 
[20] A. Doménech-Carbó, M.T. Doménech-Carbó, M.A. Peiró-Ronda, I. Martínez-Lázaro, J. Barrio, J. Solid State Electrochem. 2012, 16, 2349.

[21] C. DeGrigny, G. Guibert, S. Ramseyer, G. Rapp, A. Tarchini, J. Solid State Electrochem. 2010, 14, 425.

[22] N. Souissi, L.Bousselmi, S. Khosrof, E. Triki, Mater. Corros. 2004, 55, 284.

[23] N. Souissi, E. Triki, L. Bousselmi, S. Khosrof, Mater, Corros. 2006, 57, 794.

[24] N. Souissi, E. Triki, Mater. Corros. 2009, 60, 262.

[25] A.L. Mata, M.M.L. Salta, M.M.M. Neto, M.H. Mendonça, I.T.E. Fonseca, Mater. Corros. 2010, 61, 205.

[26] S. Feliu, M. Morcillo, S. Feliu Jr., Corros. Sci. 1993, 34, 415.

[27] J.W. Spence, F.H. Haynie, F.W. Lipfert, S.D. Cramer, L.G. McDonald, Corrosion 1992, 48, 1009.

[28] S. Bhattachariee, N. Roy, A.K. Dey, M.K. Banerjee, Corros. Sci. 1993, 34, 573.

[29] J. Kobus, Mater. Corros. 2000, 5, 104.

[30] R. Balasubramaniam, T. Laha, A. Srivastava, Mater. Corros. 2004, 55, 194.

[31] N. Matesan, G. Venkatachari, N. Palaniswamy, Corros. Sci. 2006, 48, 3584.

[32] A. Doménech-Carbó, M.T. Doménech-Carbó, T. Pasíes, M.C. Bouzas, Electroanalysis 2012, 24, 1945.

[33] L. Young, Anodic Oxide Films, Academic Press, New York, 1961.

[34] O. Rosas-Camacho, M. Urquidi-Macdonald, D.D. Macdonald, ECS Trans. 2009, $19,143$.

[35] D.D. Macdonald, G.L. Engelhardt, ECS Trans. 2010, 28, 123.

[36] F. Sharifi-Asl, M.L. Taylor, Z. Lu, G.L. Engelhardt, B. Kursten, D.D. Macdonald, Electrochim. Acta 2013, 102, 161.

[37] D.D. Macdonald, Electrochim. Acta 2011, 56, 1761.

[38] A. Doménech-Carbó, M. Lastras, F. Rodríguez, L. Osete-Cortina, J. Solid State Electrochem. 2014, 18, 399.

[39] D. Blum, W. Leyffer, R. Holze, Electroanalysis 1996, 8, 296

[40] V. Costa, M. Dubus, Impact of the environmental conditions on the conservation of metal artifacts: an evaluation using electrochemical techniques, in Museum Microclimates, T. Padfield, Ed. The National Museum of Denmark, 2007, pp. 63-65.

[41] A. Doménech-Carbó, M.T. Doménech-Carbó, M.A. Peiró-Ronda, Electroanalysis 2011, 23, 1391. 
[42] D.A. Scott, Copper and Bronze in Art -corrosion, colorants, conservation-.The Getty Conservation Institute, Los Angeles, 2000.

[43] M.T.S. Fair, L. Guerrero, O.L. Arenas, P.K. Fair, Appl. Surf. Sci. 1999, 150, 143.

[44] D.A. Scott, Stud. Conservat. 1997, 42, 93.

[45] A. Doménech-Carbó, M.T. Doménech-Carbó, I. Martínez-Lázaro, Anal. Chim. Acta 2010, 680, 1 .

[46] A. Doménech-Carbó, M.T. Doménech-Carbó, T. Pasíes, M.C. Bouzas, Electroanalysis 2011, 23, 2803.

[47] W.S. Li, S.Q. Cai, J.L. Luo, J. Electrochem. Soc. 2004, 151, B220.

[48] W. Liu, H. Zhang, Z. Qu, Y. Zhang, J. Li, J. Solid State Electrochem. 2010, 14, 965.

[49] L.A. Toledo-Martos, M.A. Pech-Canul, J. Solid State Electrochem. 2011, 15, 1927.

[50] J.J. Park, S.-I. Pyun, J. Solid State Electrochem. 2003, 7, 380.

[51] M.A.M. Ibrahim, D. Pongkao, M. Yoshimura, J. Solid State Electrochem. 2002, 6, 341.

[52] Z. Xia, H. Nanjo, T. Aizawa, M. Kanakubo, M. Fujimura, J. Onagawa, Surf. Sci. 2007, 601, 5133 .

[53] P. Acevedo-Peña, G. Vázquez, D. Laverde, J.E. Pedraza-Rosas, I. González, J. Solid State Electrochem. 2010, 14, 757.

[54] F. Fabregat-Santiago, J. Bisquert, G. García_Belmonte, G. Boschloo, A. Hagfeldt, Solar Energ. Mater. Solar Cells 2005, 87, 117.

[55] I. Rubinstein, E. Sabatani, and J. Rishpon, J. Electrochem. Soc. 1987, 134, 3078.

[56] S.-J. Lee, S.-L. Pyun, J. Solid State Electrochem. 2007, 11, 829.

[57] L. Robbiola, I. Queixalos, L.P. Hurtel, M. Pernot, C. Volfovsky, Stud. Conservat. 1988, 33, 205.

[58] I. Sandu, C. Marutoiu, I.G. Sandu, A. Alexandru, A.V. Sandu, Acta Universitatis Cibinensis Sect. F Chemia 2006, 9, 39.

[59] A. Doménech-Carbó, M.T. Doménech-Carbó, H.G.M. Edwards, Anal. Chem. 2008, $80,2704$.

[60] N. Mora, E. Cano, J.L. Polo, J.M. Puente, J.M. Bastidas, Corros. Sci. 2004, 46, 563.

[61] J.M. Bastidas, J.L. Polo, E. Cano, C.L. Torres, N. Mora, Mater. Corros. 2000, 51, 712.

[62] J. Xu, W. Huang, R.L. McCreery, J. Electroanal. Chem. 1996, 410, 235. 
[63] F. Kuang, D. Zhang, Y. Li, Y. Wan, B. Hou, J. Solid State Electrochem. 2009, 13, 385.

[64] G. Chen, C.C. Waraksa, H. Cho, D.D. Macdonald, T.E. Mallouk, J. Electrochem. Soc. 2003, 150, E423. 
Table 1. Studied coins from the Antonio Doménech Francés collection. ${ }^{a}$ the date used for calibration purposes was that indicated or the central date in the provided interval.

\begin{tabular}{|c|c|c|c|}
\hline Reference & Coin data & Country & Year $^{\mathrm{a}}$ \\
\hline ADF01 & Philippus IV & Spain & 1663 \\
\hline ADF03 & Carolus IV & Spain & 1793 \\
\hline ADF04 & Carolus IV & Spain & 1803 \\
\hline ADF06 & Republique Française, 5 cts. & France & 1916 \\
\hline ADF07 & Napoleon III, 5 cts & France & 1864 \\
\hline ADF08 & Republique Française, 10 cts. & France & 1916 \\
\hline ADF09 & Philippus IV & Spain & 1664 \\
\hline ADF10 & Republique Française, 10 cts. & France & 1871 \\
\hline ADF11 & Isabel II, 5 cts & Spain & 1868 \\
\hline ADF12 & Republique Française, 5 cts. & France & 1904 \\
\hline ADF13 & Carolas I, 20 reis & Portugal & 1892 \\
\hline ADF14 & Emmanuel de Rohan & $\begin{array}{l}\text { Rohan- } \\
\text { Polduc }\end{array}$ & 1770 \\
\hline ADF15 & $2 \mathrm{cts} / 2$ gramos & Spain & 1870 \\
\hline ADF16 & Philippus V & Spain & 1709 \\
\hline ADF18 & Helvetic Republic, 1 ct. & Swiss & 1962 \\
\hline ADF19 & Victoria, half penny & England & 1890 \\
\hline ADF20 & Isabel II & Spain & 1849 \\
\hline ADF21 & George $\mathrm{V}$, one cent & $\begin{array}{l}\text { Hong } \\
\text { Kong }\end{array}$ & 1924 \\
\hline & & & \\
\hline
\end{tabular}




\section{Figures}

Figure 1. Photograph of copper vessels, dated ca. 1260 (Mamluk period) from Jordan (Phot. Abd Al Rahman Al Srouji).

Figure 2. Simplified scheme illustrating the kinetic model used for describing the ageing of copper/bronze artifacts.

Figure 3. SWV for: a-c) samples from a copper vessel (Jordan, Mamluk period), and d) nantokite, attached to graphite bars in contact with a,b) $0.25 \mathrm{M} \mathrm{HAc} / \mathrm{NaAc}, \mathrm{pH} 4.75$; c,d) $0.10 \mathrm{M}$ potassium phosphate buffer, $\mathrm{pH}$ 7.0. Potential scan initiated at $+0.75 \mathrm{~V}$ in the negative direction; potential step increment $4 \mathrm{mV}$; square wave amplitude $25 \mathrm{mV}$; frequency $5 \mathrm{~Hz}$.

Figure 4. Equivalent circuit used to model EIS data for coins immersed into mineral water at an applied potential of $-0.60 \mathrm{~V}$.

Figure 5. Theoretical variation of the different contributions to the dating relative uncertainty for: a) VMP and b) EIS experiments. a) From Eq. (20) taking $A=2.3 ; B=$ 1000, and $a=b=0.95$ and assuming $\Delta i_{\mathrm{p}} / i_{\mathrm{p}}=0.02$; b) From Eq. (22) taking $C=500, D$ $=100, \gamma=0.07$.

Figure 6. Dating of samples from copper vessel (dated 1260) and a fragment from a Roman sculpture (dated ca. 50) using the calibration graph for copper dating using voltammetric data reported in [12] (triangles). Red squares denote data points for the samples.

Figure 7. a) Nyquist and b) Bode plots for a eurocent coin immersed into air-saturated mineral water upon application of a bias potential of $-0.60 \mathrm{~V}$. Data correspond to two replicate experiments with two different immersion plus clamp configurations (filled and empty figures, respectively). 
Figure 8. Experimental EIS of coin ADF08 immersed into mineral water (solid circles) and theoretical spectra (red lines) using the the equivalent circuit in Figure 4 inserting $R_{\mathrm{s}}=$ $10 \Omega \mathrm{cm}^{-2}, \mathrm{R}_{1}=1882 \Omega \mathrm{cm}^{-2}, Q_{1}=4.2 \times 10^{-9} \mathrm{~F} \mathrm{~cm}^{-2}, n_{\text {corr }}=0.90, R_{\mathrm{mp}}=8368 \Omega \mathrm{cm}^{-2}$, $R_{\mathrm{ps}}=24930 \Omega \mathrm{cm}^{-2}, R_{\mathrm{ss}}=6 \mathrm{k} \Omega \mathrm{cm}^{-2}, W=1.02 \times 10^{-12} \Omega \mathrm{cm}^{-2}, Q_{\mathrm{ps}}=2.5 \times 10^{-11} \mathrm{~F}$ $\mathrm{cm}^{-2}, n_{\text {pas }}=0.76, Q_{\mathrm{dl}}=2.9 \times 10^{-6} \mathrm{~F} \mathrm{~cm}^{-2}, n_{\text {corr }}=0.69$. Applied potential $-0.60 \mathrm{~V}$.

Figure 9. Values of the maximum phase angle and the logarithm of the total impedance at $0.1 \mathrm{~Hz}$ for replicate EIS experiments from 'fresh' (rhombs) and 'aged' (squares) eurocent coins and coin ADF06 (triangles), dated in 1916.

Figure 10. Variation of the maximum phase angle at intermediate frequencies with the nominal age of several coins in this study. From five replicate EIS experiments for each coin in contact with mineral water. The continuous curve corresponds to the fit of the data to a potential equation.

Figure 11. Calibration graph using the mean value of the apparent charge transfer resistance $\left(R_{\mathrm{ct}}{ }^{\text {app }}\right.$, see text) from five replicate EIS experiments for coins in this study. The continuous curve corresponds to the fit of the data to Eq. (21), inserting $C=500, D=100$, $\gamma=0.07$. 
Figure 1.

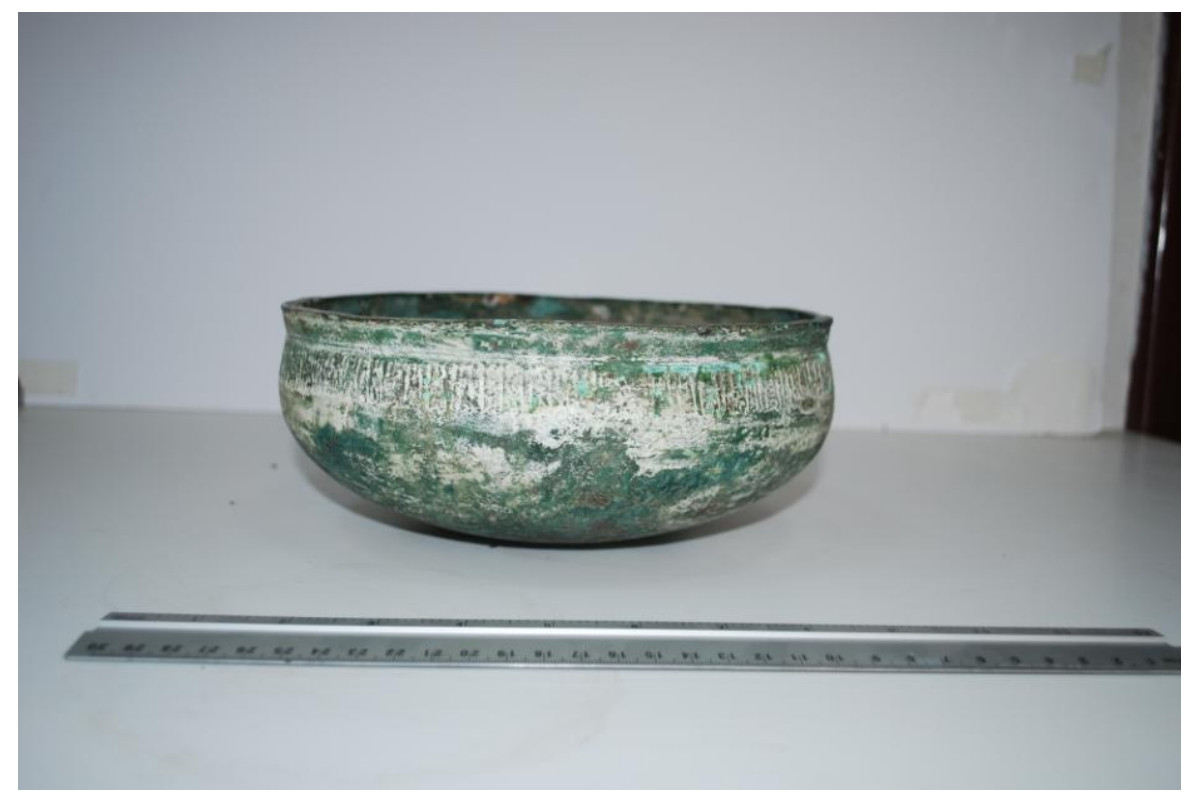


Figure 2.

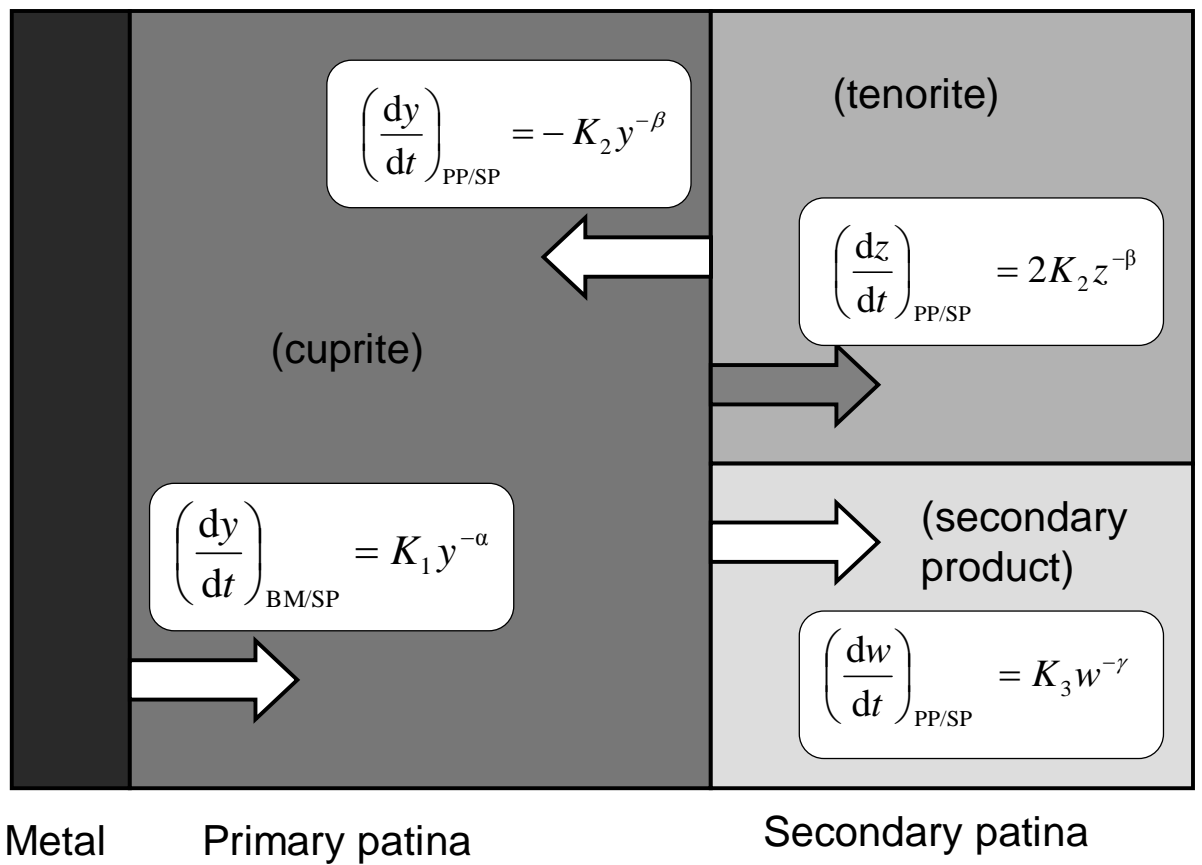


Figure 3.

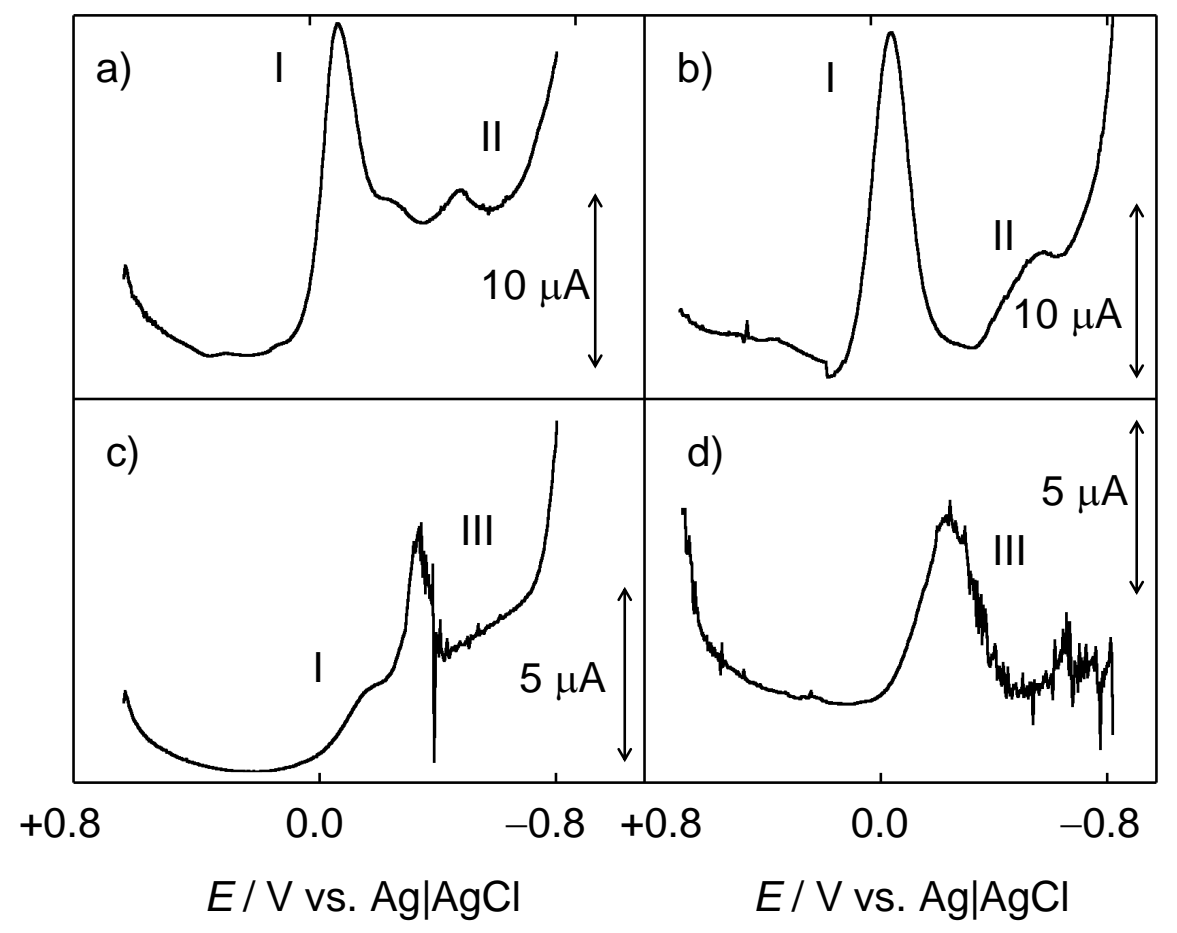


Figure 4.

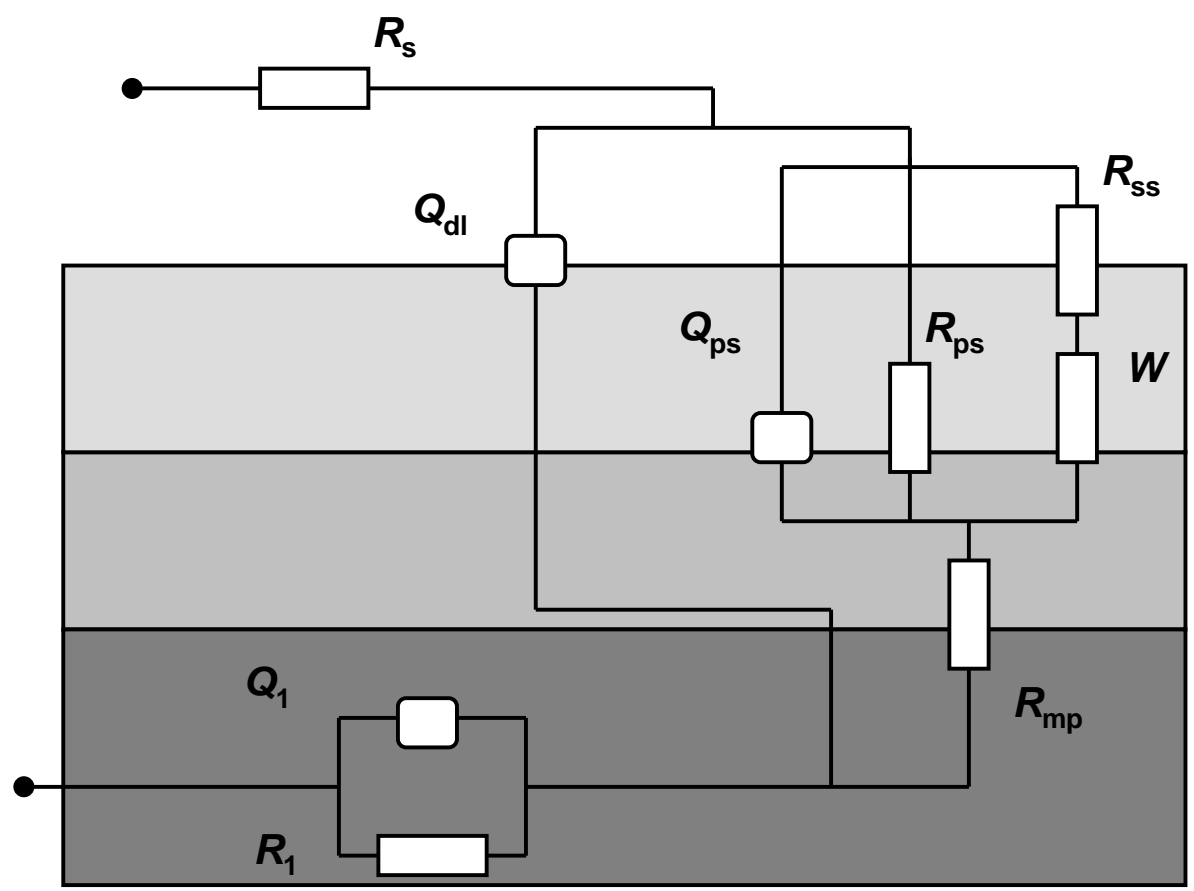


Figure 5.
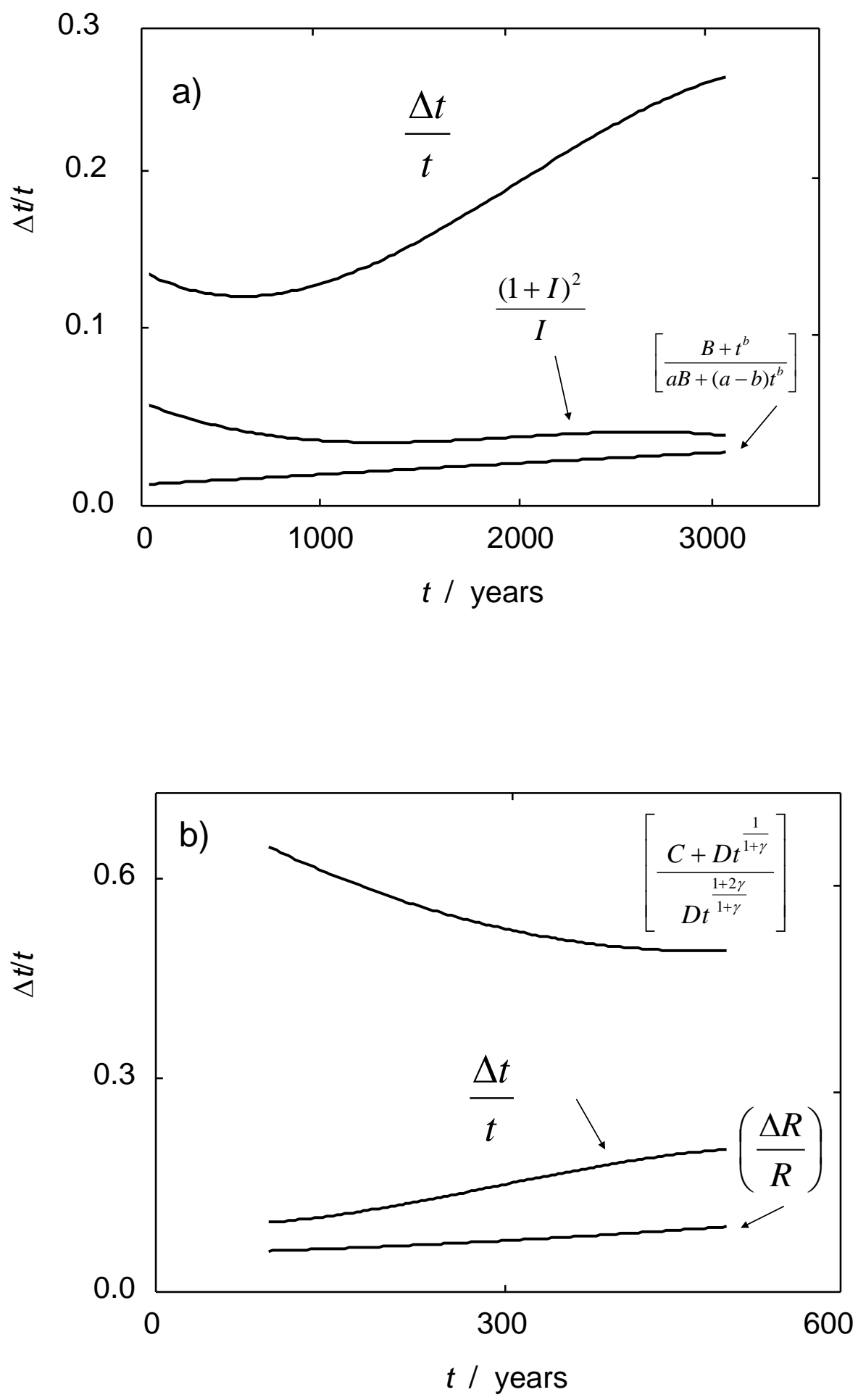
Figure 6.

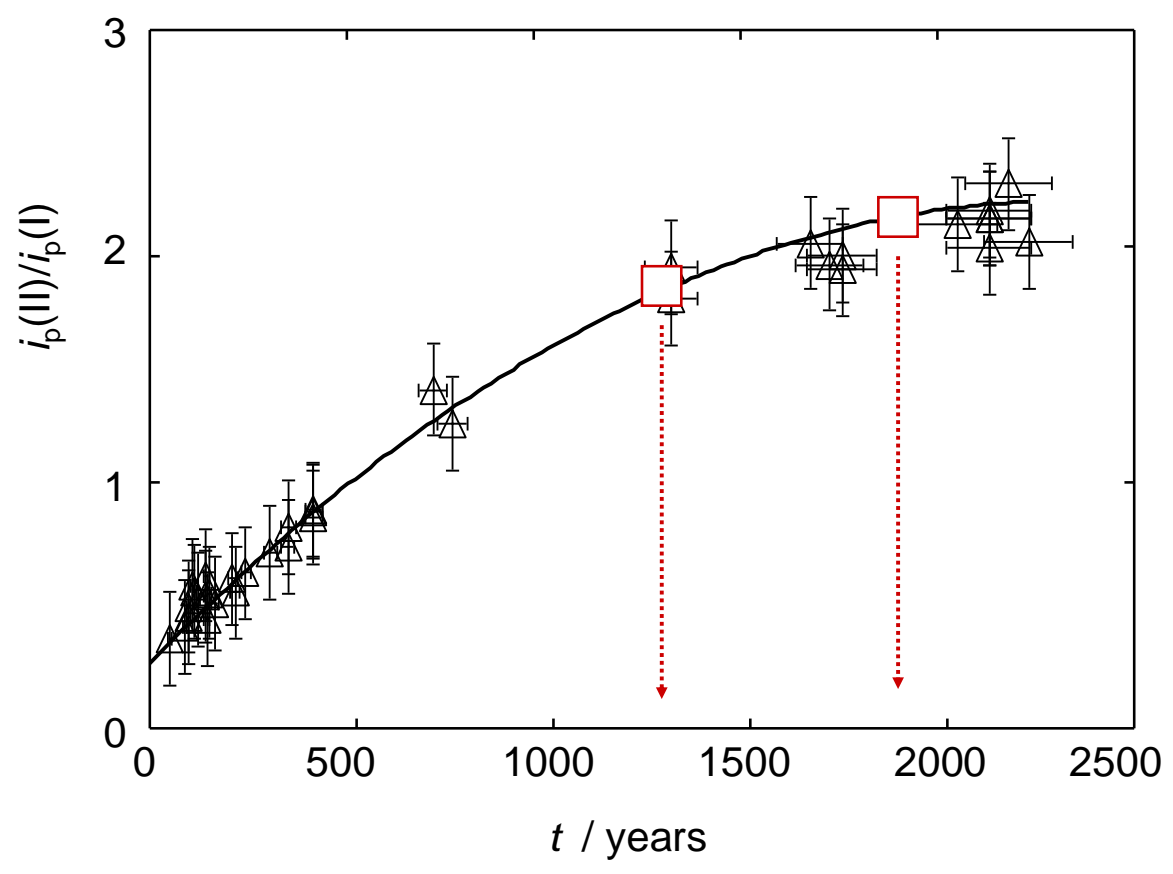


Figure 7.
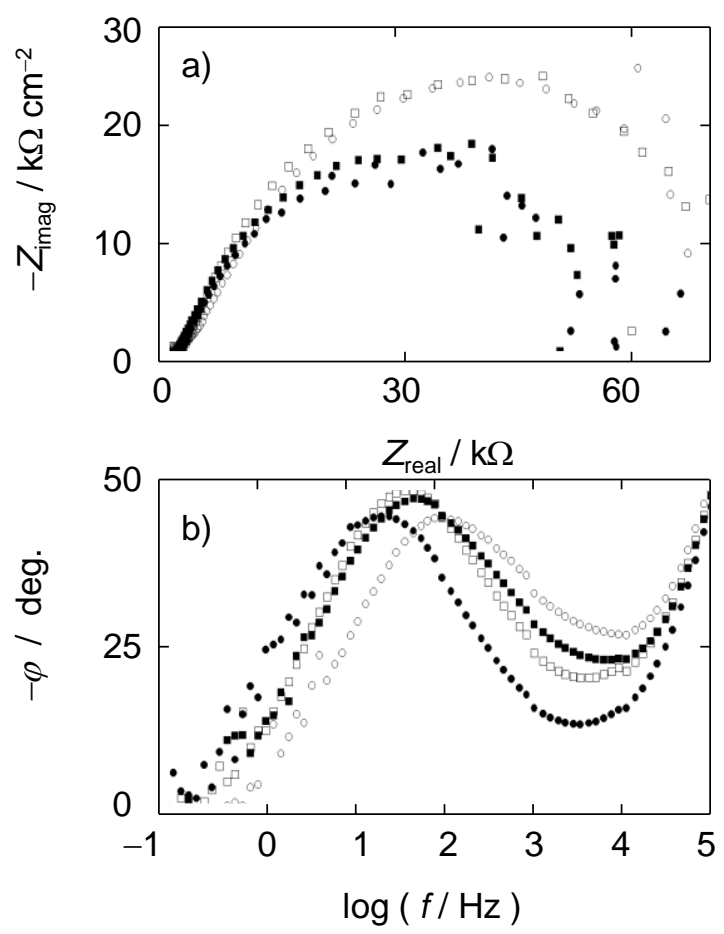
Figure 8.
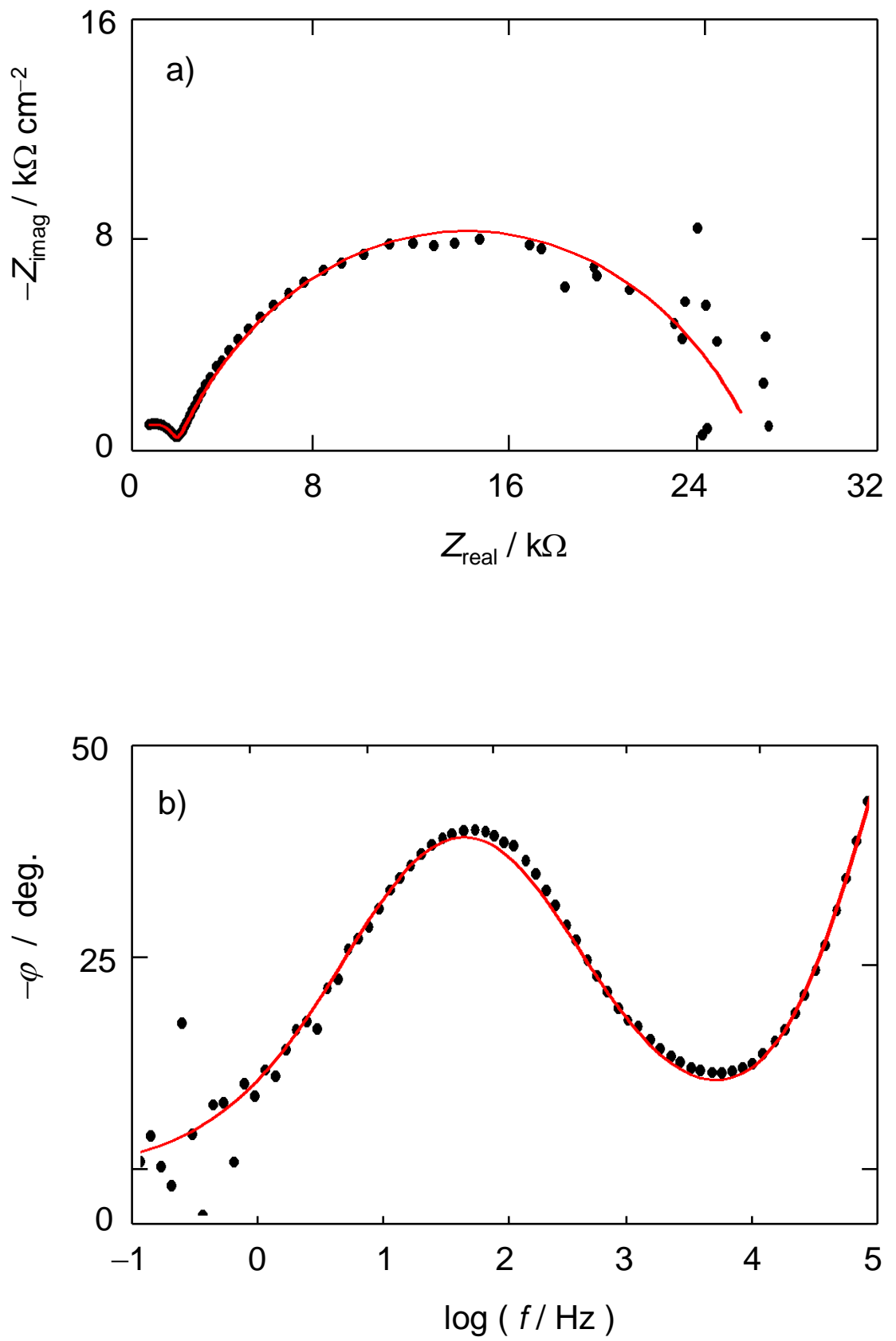
Figure 9.

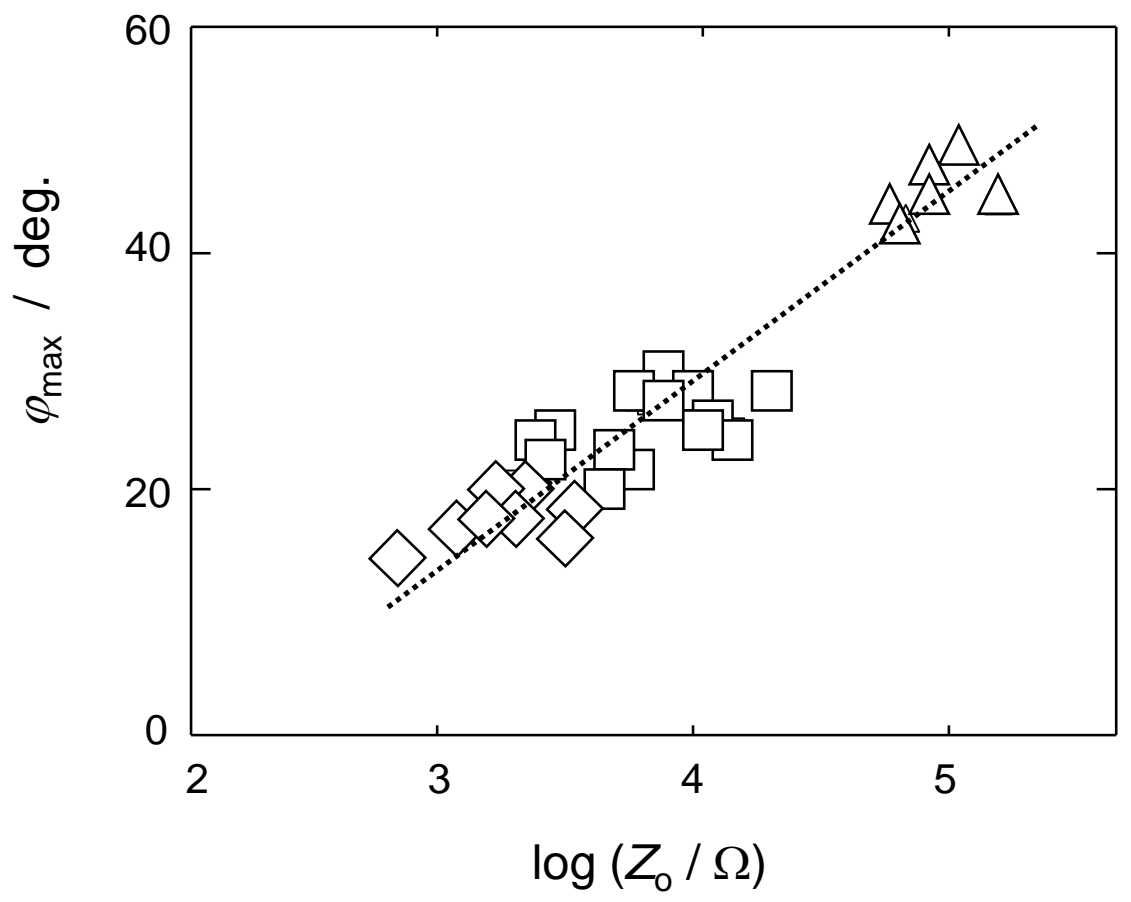


Figure 10.

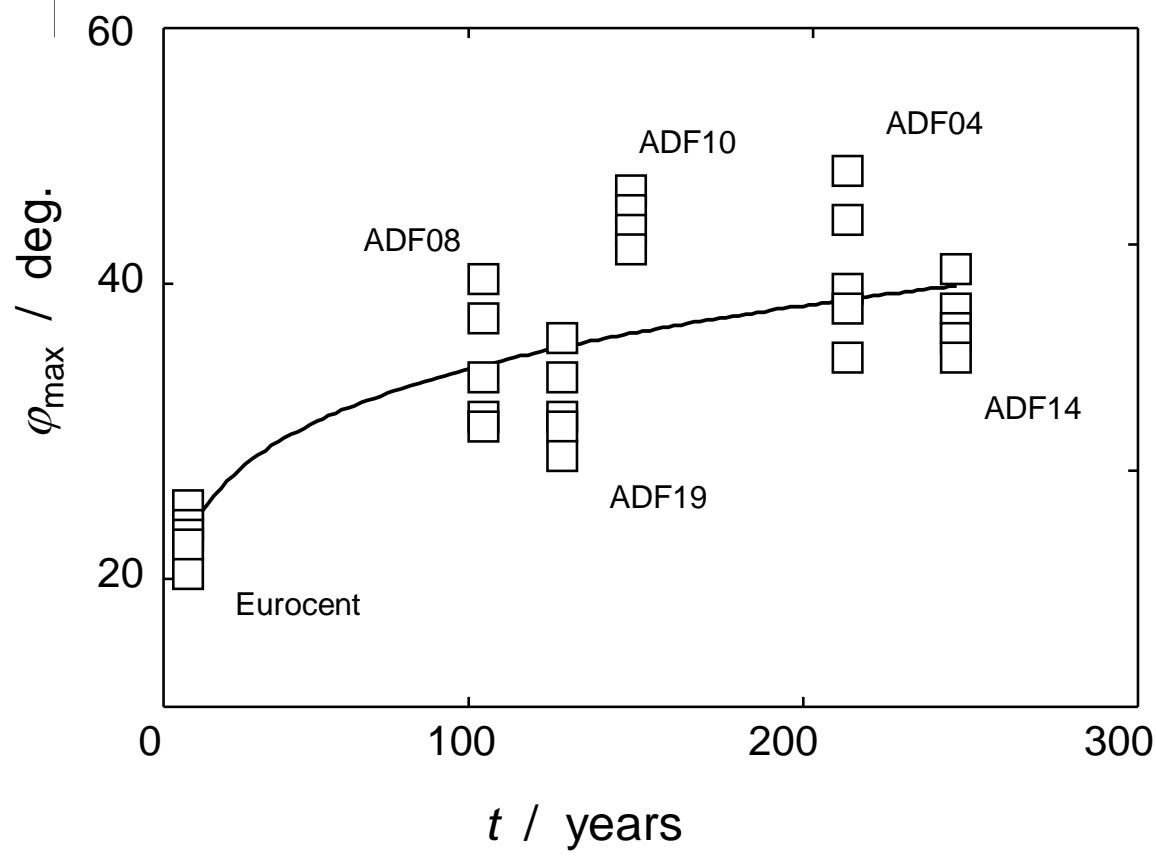


Figure 11.

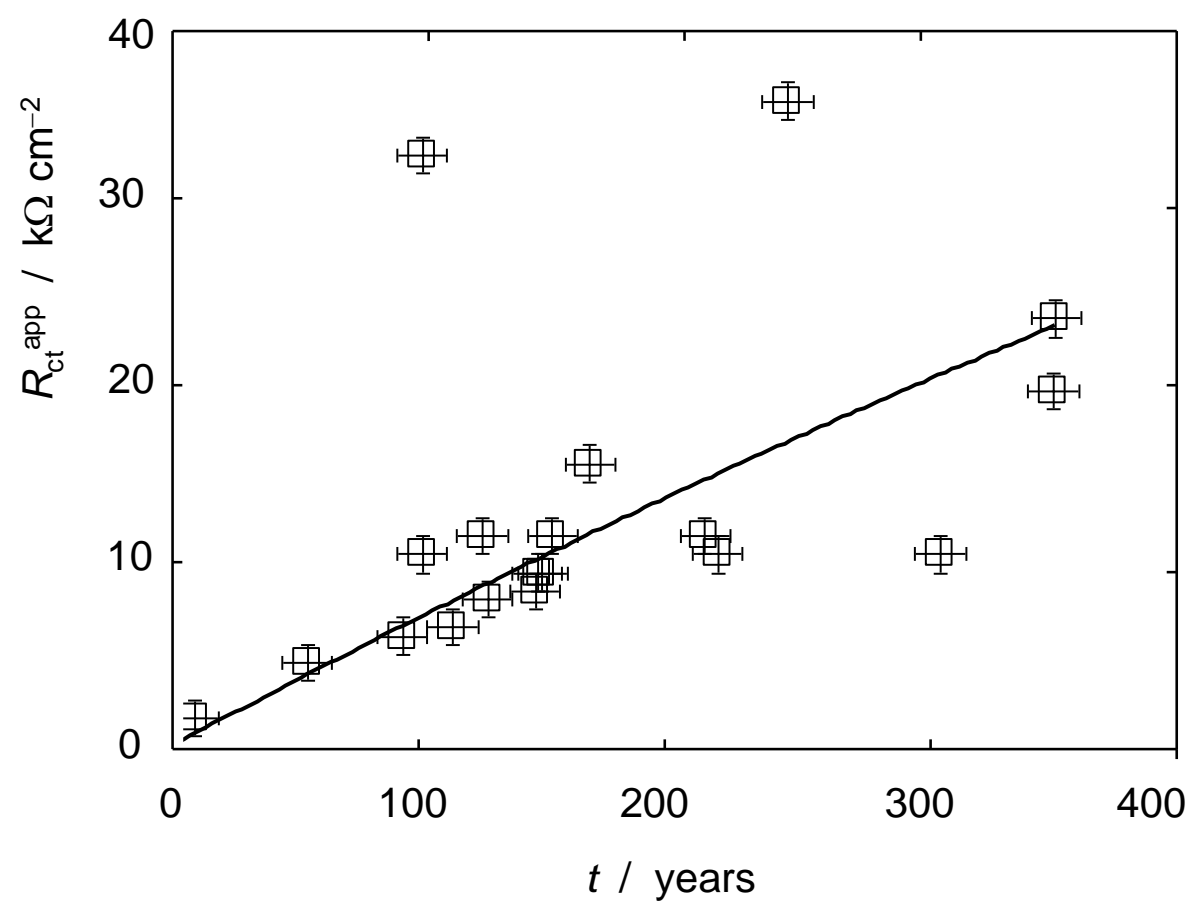

